\title{
Morphological Relationship Between the Superficial Cortical and Deep Grey Matter Structures in Adult Human Brains: A Cadaveric Study
}

\author{
Relación Morfológica entre las Estructuras Superficiales de la Sustancia Gris Cortical \\ y Profunda en los Cerebros Humanos Adultos: Un Estudio en Cadáveres
}

Azu Onyemaechi Okpara ${ }^{1,2}$; Naidu Edwin Coleridge Stephen ${ }^{1}$ \& Haghegh Eman Yacob ${ }^{1}$

\begin{abstract}
AZU, O. O.; NAIDU, E. C. S. \& HAGHEGH, E. Y. Morphological relationship between the superficial cortical and deep grey matter structures in adult human brains: A cadaveric study. Int. J. Morphol., 37(4):1437-1443, 2019.

SUMMARY: While various neurodegenerative diseases affect cortical mass differently, finding an optimal and accurate method for measuring the thickness and surface area of cerebral cortex remains a challenging problem due to highly convoluted surface of the cortex. We therefore investigated cortical thickness in a sample of cadaveric specimens at the Discipline of Clinical Anatomy, Nelson R Mandela School of Medicine, University of KwaZulu-Natal, South Africa to provide some clue as to possible variations in the parameters. Following ethical approval, 60 brain samples were uniformly sectioned (5 mm thickness) and eight slices taken from each brain across regions of interest (ROI) prepared and stained by Mulligan's technique. Thickness was measured at selected angles $\left(0^{\circ}, 45^{\circ}, 90^{\circ}, 135^{\circ}\right.$ and $180^{\circ}$ ) for both right and left cerebral hemispheres. Mulligan's stain produced good cortical differentiation and clear images that enabled manual delineation of structures. Cortical thickness ranged from 3 to 5 millimeters across the ROI. Interestingly, there was rightward hemispheric asymmetry of cortical thickness of selective slices at suggested angles which is related to structurally and functionally important brain regions. Moreover, there was no significant correlation between the surface area of superficial cortex and the deep nuclei at the same level. The superficial cortex and deep nuclei are manifested independently in normal aging, neuropsychiatric or developmental disorders. Providing accurate morphometric evaluation of cortical thickness and area based on gross staining of the brain slices could provide qualitative data that may support the study of human cerebral cortex even in disease conditions.
\end{abstract}

KEY WORDS: Brain; Morphometrty; Mulligan stain; Gray matter.

\section{INTRODUCTION}

While the cerebral cortex is largely responsible for higher brain functions, including sensory and motor activity, differential cortical involvement in numerous neurodegenerative pathologies of the brain exists with regards to morphology. For instance, Alzheimer's disease (AD) is known to cause degeneration of limbic and heteromodal regions of the cerebral cortex whereas in Huntington's disease (HD) progressive striatal degeneration occurs with the level of cortical involvement unknown (Rosas et al. 2002). In addition to this, establishing a clear morphological mapping of brain regions (cortical or deep) that are affected by various diseases remains a challenge. Much of what is known were based on postmortem sections of the brain Morrison and Hof (2002) but more sophisticated methods involving magnetic resonance imaging (MRI) in- vivo techniques have evolved in recent times enabling quantitative neuroanatomical assessment of cortical involvement in diseases of the brain.

However, there are more pertinent challenges with regards to assessment of cortical thickness in human brain samples due to the complex folding patterns and regional variability (Rosas et al. 2002). Different methods have been adopted to provide an accurate and efficient morphometric measurement especially for cortical thickness and surface area especially in a cohort of patients (In vivo samples). Manual methods are labor-intensive and typically focus on a few a priori-defined regions with resultant extensive slices and numerous regions that need to be studied. Therefore, to get accurate and precise results from In vivo samples,

${ }^{1}$ Discipline of Clinical Anatomy, School of Laboratory Medicine and Medical Sciences. Nelson R Mandela School of Medicine, University of KwaZuluNatal, South Africa.

${ }^{2}$ Department of Anatomy, School of Medicine, University of Namibia, Windhoek, Namibia. 
automated and highly sophisticated method of measurements such as a high-resolution T1-weighted MRI scan which require expensive devices and well trained technicians is needed (Fischl \& Dale, 2000). Other approaches that depend on volume-based deformation described by Talairach (1967) (which is a 3-D normalization of cortical surface) is fraught with poor anatomical precision and the metric properties do not reflect the distances along the cortical surfaces (Fischl et al.1999).

Therefore it is important to realize a simple and efficient technique that provides good differentiation between the gray and white matter which can be performed in an in vitro sample to overcome the measurements errors where the cortical surfaces are not perpendicular to the cardinal axes. The Mulligan's method of staining provides a simple, reliable and efficient procedure that helps to differentiate between the gray and white matter in in vitro samples (Meneses et al. 2004) and also allow for the manual estimation of cortical thickness and surface area confidently. Therefore, our study will investigate cortical thickness difference between right and left cerebral hemispheres in a random sample of adult human brains and to correlate the superficial cortical surface area with the deep nuclei. This will allow further understanding of how the cortex is affected by diseases and thus may provide important new insights into it (Rosas et al.).

\section{MATERIAL AND METHOD}

Sample of sixty adult cadaveric whole brain specimens were obtained from the Discipline of Clinical Anatomy, Nelson R Mandela School of Medicine, University of KwaZulu-Natal. Basic biographic information (e.g., age, sex and race) were recorded as well as any disease condition (if present).

Ethical Approval: The study was approved by the Biomedical Research Ethics Committee (BREC), University of KwaZulu-Natal (Reference BE 134/14) and carried out at the Department of Clinical Anatomy, School of Laboratory Medicine and Medical Sciences, University of KwaZuluNatal with adherence to regulations guiding the use of human tissues and the South African Human Tissue Act 65 of 1983.

Sample preparation: Each specimen was carefully weighed by calibrated manual scale (Hanson H005 Mechanical Weighing Scales). These scales weigh up to $3 \mathrm{kgs} / 6.6 \mathrm{lbs}$ and in increments of $20 \mathrm{~g} / 1 \mathrm{oz}$. Subsequently, each brain sample was photographed using Sony digital camera (7.2 mega pixels and 4x optical zoom), numbered in order and then transferred into a preservative solution with the following constituents (mixture of $12.5 \mathrm{ml}$ phenol, $50 \mathrm{ml}$ of $40 \%$ formalin, 1 liter pine oil, $927.5 \mathrm{ml}$ ethanol and 1 liter glycerin) in 1 liter of water.

Brain slicing: After properly aligning each brain sample, serial coronal sections $5 \mathrm{~mm}$ thick were obtained from each brain specimen using the Russel Hobbs food slicer (Model: RHFS-01/02) which is designed to produce slice thickness from 0 - $15 \mathrm{~mm}$. five $\mathrm{mm}$ thickness was chosen to minimize distortions of slices and ensure consistency and stability. Slices were carefully handled and preserved in labelled plastic containers with the same preservative solution, taking into account the order of consecutive slices. They were approximately 17 - 20 slices per brain sample. These sections were defined carefully by region of interest (ROI) depending on the visual observation of the deep nuclei (caudate nucleus, putamen and globus pallidus). Hence, only eight coronal sections were selected for this study per brain starting from the $6^{\text {th }}$ slice (frontal-occipital direction) with subsequent eight slices carefully chosen.

Staining: After a trial (pilot) phase on the choice of stain between the Barnard and Mulligan's techniques, the later was adopted due to better differentiation between the gray and white matter (as indicated in Meneses et al.) and good efficacy of the technique in terms of shorter time, less volume of chemicals and cost effectiveness because each solution can be used more than once and stains 25 to 30 slices.

Mulligan method (Gregg, 1975): Staining solution is composed of phenol $40 \mathrm{~g}$, copper sulfate $5 \mathrm{~g}$ and $1.25 \mathrm{ml}$ hydrochloric acid in 1 liter of water. The slices were soaked for 4 minutes at $60-65^{\circ} \mathrm{C}$ in a bath warmer LABOTEC (model No. 420), in a Mulligan solution. Then, washed by ice water for 10 seconds and subsequent immersion in 0.4 $\%$ tannic acid for 1 minute at room temperature. After further soaking in the water for 1 minute, the slices were put in 0.08 $\%$ ferric ammonium sulfate at room temperature for $10-15$ seconds. Then another washing in running water for 8 hours (this was modified to 30 minutes soaking in water in order to cut down on time). This adjustment gave same result when compared with the 8 hour stated.

Gray matter demarcation: Immediately after the staining, each slice was carefully handled and dried by paper towel and put in transparency file while achieving consistency and stability of each slice with minimal distortion. Under appropriate illumination and good visual observation of gray matter and regions of interest, outlines of superficial and deep gray matter were manually drawn using a waterproof permanent marker $0.6 \mathrm{~mm}$, (Model: edding 141F). Similar steps were followed on the eight slices from each brain. Each 
transparency was properly numbered according to the sequence of the sample and slice and the image scanned using KONICA MINOLTA Bizhub 211 Office printer scanner. The outlines of each slice drawing were highlighted with BIC chisel tip permanent markers for more demarcation of gray matter. Thereafter, each scanned copy is saved as picture file in organized manner subsequent to measurement of thickness and surface area of the cerebral gray matter.

Gray matter measurements: All saved copies of each slice were printed out for manual measurement of cerebral cortical thickness of both cerebral hemispheres. Cortical thickness was measured at selected area and at chosen angle $\left(0^{\circ}, 45^{\circ}\right.$, $90^{\circ}, 135^{\circ}$ and $180^{\circ}$ ) for both right and left hemispheres. These angles were selected because planes would cross over important gyri and sulci (for example, angle $90^{\circ}$ crossed over the lateral sulcus in most of the slice). The angles were marked and measured by positioning the protractor at the center of each slice and carefully notingthe intersection of axes. The thickness was then read off at suggested angles (using a metric rule) in millimeters. For surface area, both the superficial cortex and deep nuclei were measured using the paint.net 4.0.6 software which contour and calculates the surface area of selected region (in $\mathrm{mm}^{2}$ ) automatically. All data are collated in excel sheet for subsequent analyses.

Statistical analysis: Data were subjected to formal descriptive statistics for cortical thickness at suggested angles $\left(0^{\circ}, 90^{\circ}\right.$, $135^{\circ}$ and $180^{\circ}$ ) for both right and left cerebral hemispheres. Surface area was calculated for both superficial cortex and deep nuclei. The results are expressed as mean \pm SD (standard deviation) with $95 \%$ confidence interval $(\mathrm{p}<0.05)$.

\section{RESULTS}

Of the 60 whole cadaveric brain specimens used in this study, $5(8.33 \%)$ were excluded as a consequence of damage (either pathology $2(3.3 \%)$ or trauma $3(5 \%)$ and $16(26.7 \%)$ had missing biological information. 22 (36.7 $\%)$ were males and $22(36.7 \%)$ females (male to female ratio of 1:1). Age ranged from 47 to 97 years with median age of 79.5 years and average age of $77.9 \pm 11.85$. All the 44 $(73.3 \%)$ out the 60 specimens were of white ethnicity.

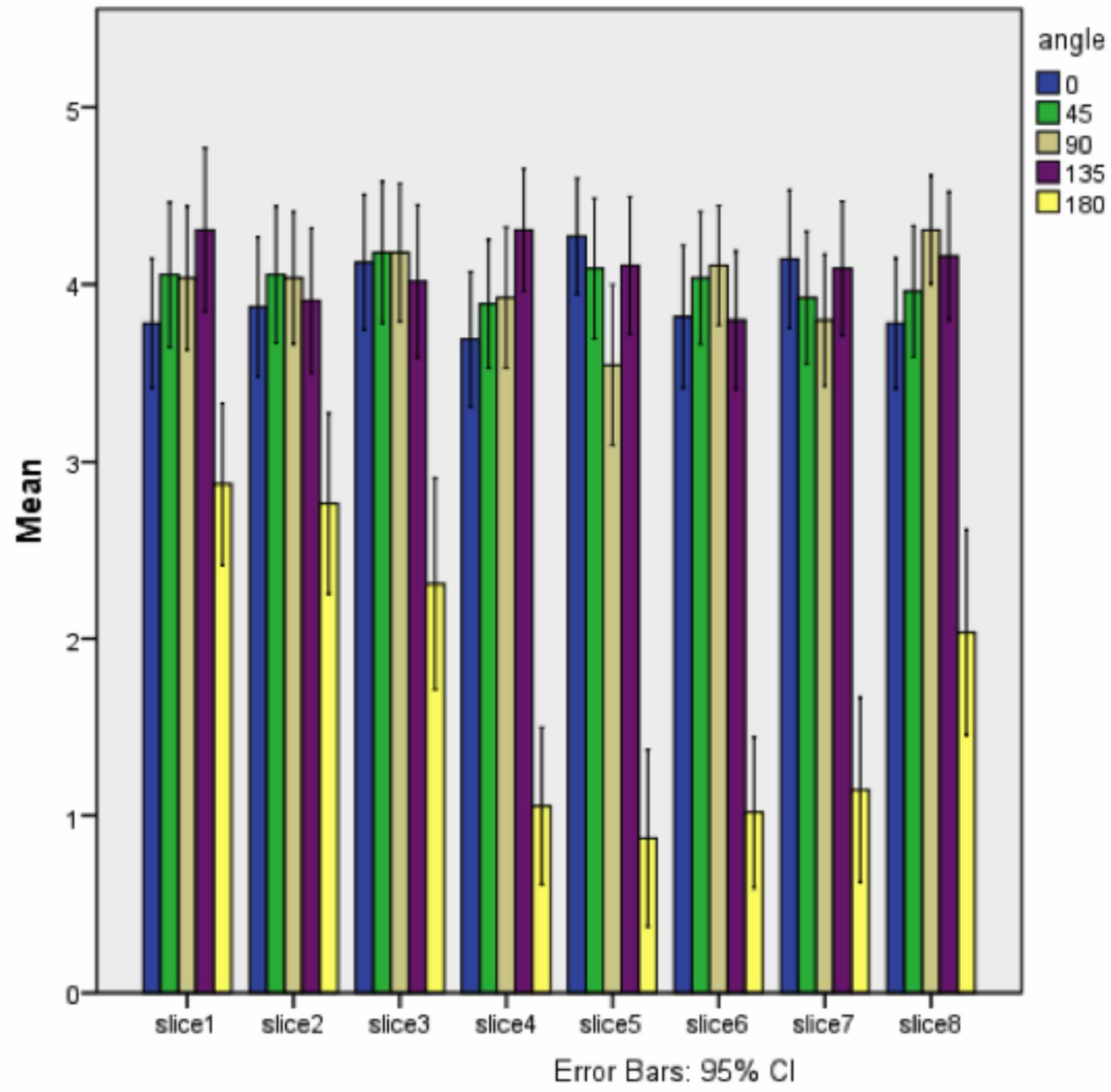

Fig. 1. Mean cortical thickness at selected angles for the slices (1-8) for the right hemisphere. 
Brain weight. Brain weight ranged from 820 - 1540 grams with a median of $1190 \mathrm{gm}$ and average of $1186.6 \pm 135.5 \mathrm{~g}$. Cortical thickness. Fifty five specimens were analysed for cortical thickness. The most frequent thickness ranged from 2 - $5 \mathrm{~mm}$ across suggested angles of measurements for both cerebral hemispheres. The thickest measurement for the right cerebral hemispheres was at angle $135^{\circ}$ in slice 1 (4.31 1.7 $\mathrm{mm})$ and for the left cerebral hemispheres was at angle $45^{\circ}$ for slice 1 (4.31 $\pm 1.7 \mathrm{~mm}$ ) (Figs. 1 and 2, respectively).

\section{Comparing the mean cerebral cortical $(\mathrm{mm})$ for the right} side gives the following values: $(4 \pm 1.44)$ slice 1 , $(4.06 \pm 1.35)$ slice $2,(4 \pm 1.47)$ slice $3,(3.92 \pm 1.39)$ slice 4 , $(3.99 \pm 1.56)$ slice $5,(4 \pm 1.35)$ slice $6,(3.93 \pm 1.36)$ slice 7 and $(4.13 \pm 1.35)$ slice 8 respectively. These values were slightly greater than the corresponding values for the left side as indicated thus; (3.72 \pm 1.71$)$ slice 1, (3.69 \pm 1.54$)$ slice 2, (3.57 \pm 1.89$)$ slice $3,(3.4 \pm 1.83)$ slice $4,(3.51 \pm 1.93)$ slice 5 , $(3.31 \pm 1.86)$ slice $6,(3.42 \pm 1.88)$ slice 7 and $(3.53 \pm 1.81)$ slice 8 (Fig. 3).
Surface areas of superficial cortex and deep nuclei: The mean of superficial cortical surface area $(8863 \pm 1977)$ for slice $1,(9531 \pm 1968)$ for slice $2,(9884 \pm 1187)$ for slice 3, $(9680 \pm 1958)$ for slice $4,(9680 \pm 1958)$ for slice 5 , $(9725 \pm 2090)$ for slice $6,(9821 \pm 1206)$ for slice 7 , (9269 \pm 2385$)$ for slice 8 are numerically larger than the deep nuclei surface area $(186 \pm 382)$ for slice $1,(556 \pm 606)$ for slice 2 , $(982 \pm 392)$ for slice $3,(1059 \pm 338)$ for slice $4,(1126 \pm$ $414)$ for slice $5,(1171 \pm 1275)$ for slice $6,(805 \pm 1368)$ for slice 7, $(444 \pm 1100)$ for slice 8, as shown in Figure 4.

\section{DISCUSSION}

The cerebral cortex, memory, reasoning, and thought Kandel et al. (2000). It is composed of highly convoluted sheet of gyri and sulci that accommodate a large number of neurons arranged in columns, which serve as a basic unite of information process. The cortical surface area is proportional to neurons number and therefore it is related to the functional ability. In addition, the cortical thickness of certain areas are also related to the function ability and any changes in these features will definitely affect the brain function and therefore there will be a variety of neurological and psychiatric diseases (Thompson et al., 2003; Janssen et al., 2009). Moreover, studying of cortical thinning are potentially useful in assessing the efficacy of a wide range of treatments. A morphometric measurements of the cortex is considering one of the methods that helps in understanding the brain structure and function.

Moreover, accurate, reliable and efficient measurements of cortex remain a challenging difficulty due to sulco-gyral folding pattern.

The cortical thickness is considered one of the important and interesting measures that attract the attention of most neuroscientists and this 


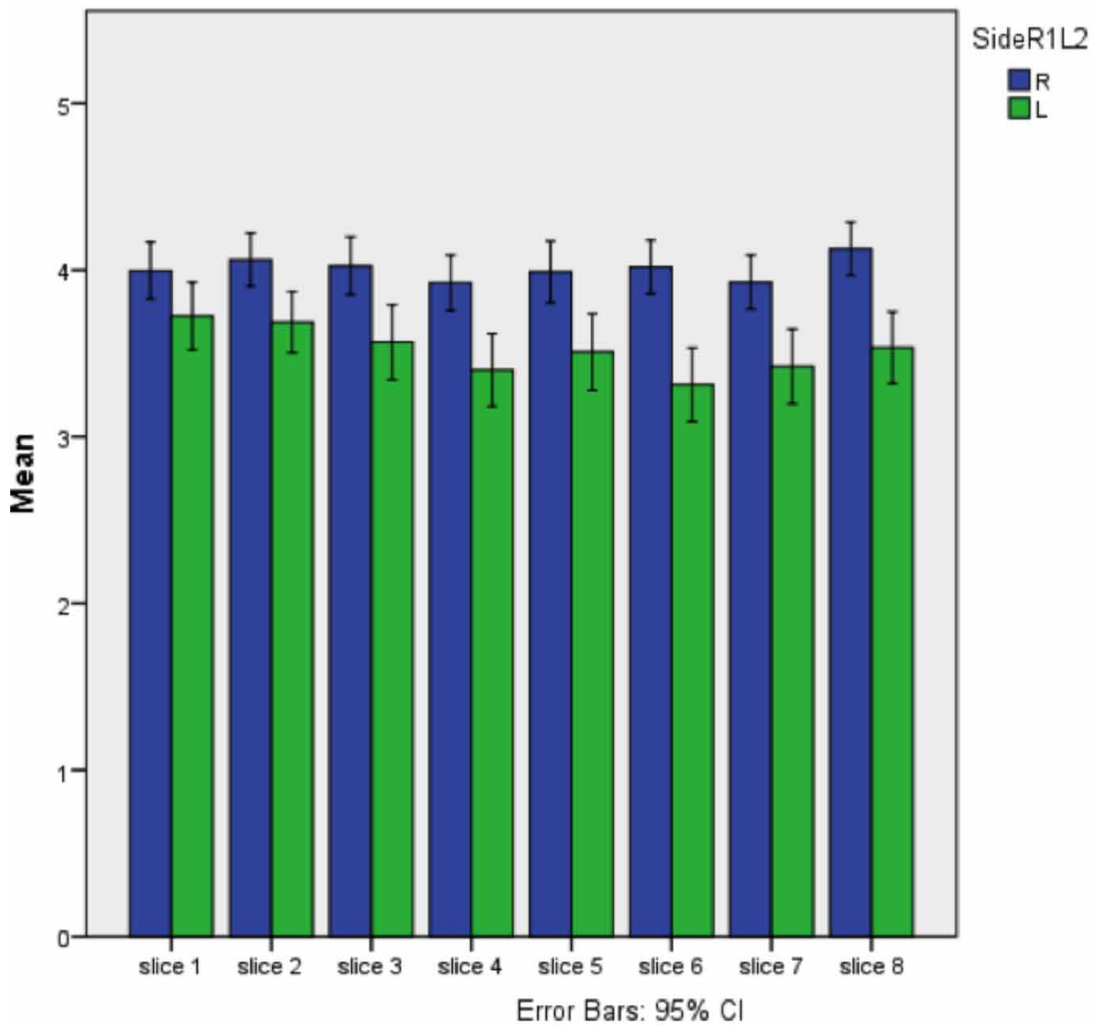

Fig. 3. Comparative mean cortical thickness between right and left hemispheres.

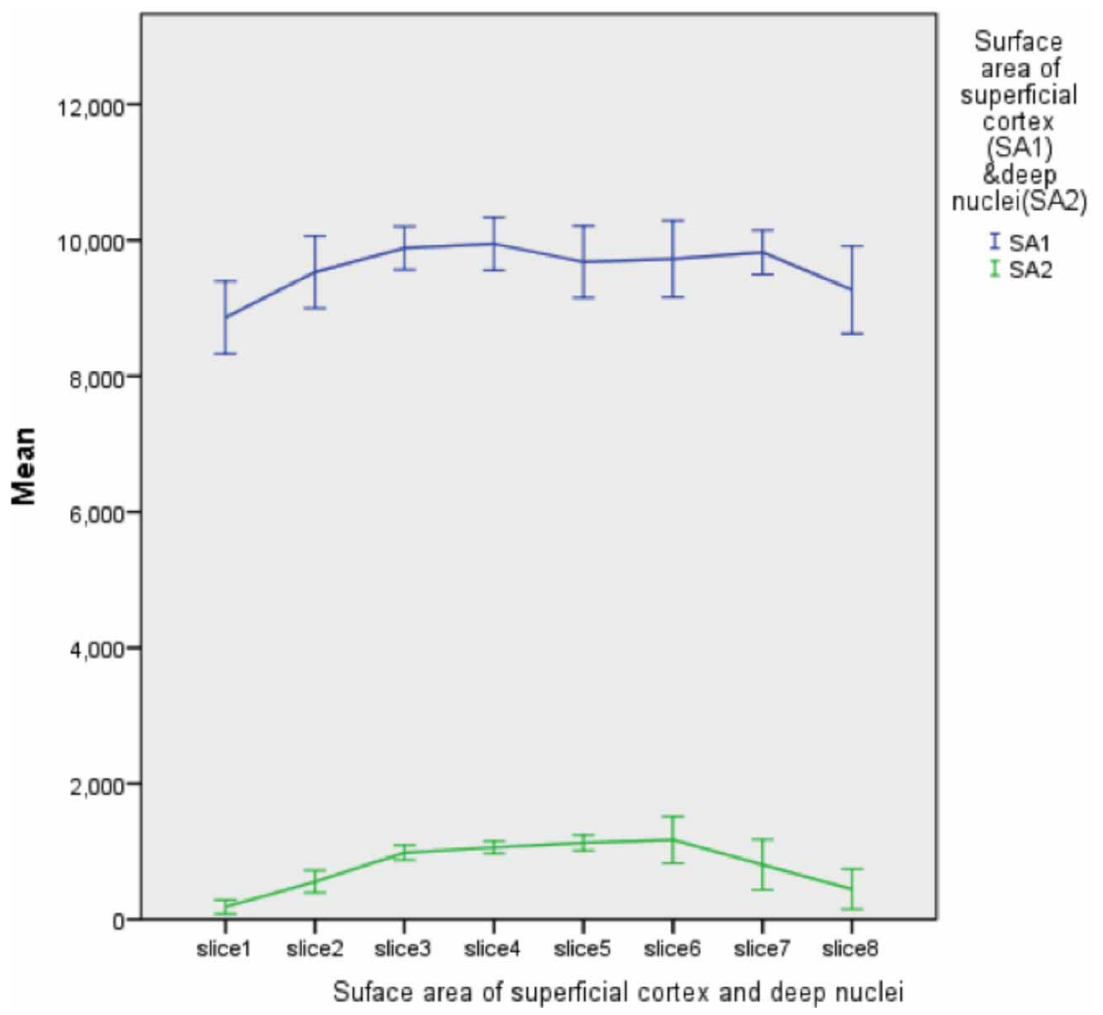

Fig. 4. The difference between the mean of superficial cortex and deep nuclei. importance appears in both normal as well as in diseased conditions. Especially, the alterations in the superficial and deep gray matter can be manifested in aging (De Leon et al., 1997; Jack et al., 1997), Huntington's disease (Vonsattel \& DiFiglia, 1998; Walker, 2007), schizophrenia (van Os \& Kapur, 2009), dementia (Kaye et al., 1997), amyotrophic lateral sclerosis (Kiernan \& Hudson, 1994), as well as in Alzheimer's disease (Thompson et al.). In contrast, cortical thinning is of great benefit in assessing the efficacy of a wide range of treatments of such diseases.

The difficulty of properly measuring the thickness and surface area of the cortex without clear demarcation between white and gray matter is the key point to obtain efficient and easy way of measurements. Therefore it is important to realize a simple and efficient technique that provide good differentiation between the gray and white matter, also this differentiation is preferable to be In vitro sample to overcome the measurements errors where the cortical surface is not perpendicular to the cardinal axes.

The method presented here provide a simple, reliable and efficient procedure that helps to differentiate between the gray and white matter In vitro sample which is Mulligan's method of staining because it has shown most effective staining technique (Meneses et al.). This approach endorsed the easiest way to outline the gyri and sulci as it is known that around (60-70\%) of gyri are buried in the sulci (Zilles et al., 1988; Van Essen et al., 1998).

Moreover, In vivo human as well as animal study samples provide less structural resolution Deng et al. (2014) and Fischl \& Dale. As mentioned before many other studies tried to do such measurements In vivo samples through different suggestions such as using high- 
dimensional warping by recording two volumes (Miller $e t$ al., 1993; Christensen et al., 1995; Joshi et al., 1997), but this does not guarantee the sulcal and gyral alignment which are the accurate landmarks for the location of functional areas (Fischl et al.). Other technique were depended on transformation and reconstruction of cortical surface to measure the distance between only two structural or functional points on the cortical surface, but this technique of transformation and reconstruction had poor accuracy because of distortion of the anatomical structure of the cortical surface (Talairach; Miller et al.; Fischl et al.). Thus, in general the accurate value of morphometric data of the cortex cannot properly achieved by such approaches, as mentioned before the cortex contains many sulco- gyral folding that are not with the same alignment of the cardinal axes. Therefore, cortical thickness and surface area obtained from such technique of measurements will not be accurate and precise to distinguish the site and progress of cortical changes. This level of precision is important in early detection of regionally specific cortical atrophy associated with early manifestations of neurodegenerative disorders such as Alzheimer disease (Thompson et al.).

Here is presenting the first study in South Africa that provide informative, comprehensive and descriptive morphometric data on the thickness of cerebral cortex and surface are of superficial and deep gray matter. Thus, we focused to evaluate superficial cortical thickness at suggested angles $\left(0^{\circ}, 45^{\circ}, 90^{\circ}, 135^{\circ}\right.$ and $\left.180^{\circ}\right)$ for both right and left cerebral hemisphere, because it appears that the measurements taken at these angles crossed through the most important areas of structure and function. For example, angle $90^{\circ}$ represented the lateral sulcus for most of specimens.

Thereafter, to address the research hypothesis that is there is slight difference between the right and left cortical thickness of cerebral hemispheres at suggested angles $\left(0^{\circ}\right.$, $45^{\circ}, 90^{\circ}, 135^{\circ}$ and $180^{\circ}$ ) and the surface area of the superficial cortex is larger than the deep nuclei. We conduct a comprehensive descriptive statistical analysis.

The most frequent thickness was ranged from 2 to 5 $\mathrm{mm}$ across suggested angles of measurements of both cerebral hemispheres throughout the slices represent the regions of interest, which full within the normal range (Kandel et al.). The thickest cortex of right cerebral hemispheres was at angle $135^{\circ}(8 \mathrm{~mm})$ of slice 1 , which associated with the numerically largest mean of thickness $(4.31 \pm 1.7)$ and the thickest cortex of left cerebral hemispheres was at angle $45^{\circ}(8 \mathrm{~mm})$ of slice 1 , which associated with the numerically largest mean of thickness $(4.31 \pm 1.7)$. Interestingly, this slice at these angles is corresponding with anatomically and functionally important areas which can be affected by disease differently.
Moreover, the right cerebral cortex thickness of selective slices at suggested angles are slightly larger than the left cerebral cortex thickness, which reflect the relationship between cortical thickness and functional specialization of each hemisphere (Paus et al., 1996; Watkins et al., 2001). In addition, the surface area of superficial cortex are numerically larger than the deep nuclei surface area. Thereafter, this results will reject the null hypothesis and at the same time will accept the research hypothesis.

\section{CONCLUSION}

Structural and functional properties of the cortex is still under survey, due to the complexity of the cortical sheath. Therefore, a number of methods have been used to elucidate and simplify the structural-functional relationship which depend on the efficacy and accuracy of the techniques used to characterize the morphometric difference between populations.

The results obtained from this study were achieved by combining the simple, efficient and proper method of comprehensive morphometric data for measures of cortical thickness, as well as surface area of superficial and deep gray matter. This can be useful in studying diseases affecting the superficial cortical thickness, as well as deep nuclei, while analyzing of the morphometric properties of cerebral cortex is of great importance in studying the changes associated with normal and diseased conditions.

Recommendations. Further comparison study of average cortical thickness and surface area across specific structural and functional regions of interest. This comparison can be carried out between patients and control groups, which can be used to correlate between the points in one cortical hemisphere with the correspondence points in the other hemisphere. This registration is of great importance in providing more information to assess the early diagnosis of certain diseases.

In addition, such comparison can be used to identify any a symmetry between the right and left cerebral cortex in equivalence regions of interest.

\section{ACKNOWLEDGEMENTS}

We thank the College of Health Sciences, University of KwaZulu-Natal Durban South Africa for the postgraduate financial support. Our gratitude to Late Mr. Salem Kharwa for his technical support in archiving specimens. 
AZU, O. O.; NAIDU, E. C. S. \& HAGHEGH, E. Y. Relación morfológica entre las estructuras superficiales de la sustancia gris cortical y profunda en los cerebros humanos adultos: un estudio en cadáveres. Int. J. Morphol., 37(4):1437-1443, 2019.

RESUMEN: Si bien varias enfermedades neurodegenerativas afectan a la masa cortical de manera diferente, encontrar un método óptimo y preciso para medir el grosor y el área de la superficie de la corteza cerebral sigue siendo un problema difícil debido a la superficie altamente enrevesada de la corteza. Por lo tanto, investigamos el grosor cortical en una muestra de cadáveres del Departamento de Anatomía Clínica de la Facultad de Medicina Nelson R. Mandela de la Universidad de KwaZulu-Natal, Sudáfrica, para proporcionar alguna pista sobre posibles variaciones en dichos parámetros. Después de la aprobación ética, 60 muestras de cerebro se seccionaron uniformemente ( $5 \mathrm{~mm}$ de grosor) y se tomaron ocho cortes de cada cerebro en regiones de interés (ROI) preparadas y teñidas con la técnica de Mulligan. El espesor se midió en los ángulos seleccionados $\left(0^{\circ}, 45^{\circ}, 90^{\circ}, 135^{\circ}\right.$ y $\left.180^{\circ}\right)$ para los hemisferios cerebrales derecho e izquierdo. La tinción de Mulligan produjo una buena diferenciación cortical e imágenes claras que permitieron la delineación manual de las estructuras. El grosor cortical osciló entre 3 y 5 milímetros a través del ROI. Curiosamente, hubo una asimetría hemisférica hacia la derecha del grosor cortical de los cortes en ángulos sugeridos que se relacionan con regiones cerebrales estructural y funcionalmente importantes. Además, no hubo una correlación significativa entre el área de la superficial de la corteza superficial y los núcleos profundos en el mismo nivel. La corteza superficial y los núcleos profundos se manifiestan de manera independiente en el envejecimiento normal, en los trastornos neuropsiquiátricos o del desarrollo. Realizar una evaluación morfométrica precisa del grosorcortical y el área basada en la tinción macroscópica de los cortes del cerebro, podría proporcionar datos cualitativos que puedan respaldar el estudio de la corteza cerebral humana incluso en condiciones de enfermedad.

PALABRAS ClAVE: Cerebro; Morfometría; Tinción de Mulligan; Sustancia gris.

\section{REFERENCES}

Christensen, G. E.; Marsh, J. L.; Miller, M. I. \& Vannier, M. W. Automatic Analysis of Medical Images Using a Deformable Textbook. Proc. Comp. Assist. Radiol., 152-7, 1995.

De Leon, M. J.; George, A. E.; Golomb, J.; Tarshish, C.; Convit, A.; Kluger, A.; De Santi, S.; McRae, T.; Ferris, S. H.; Reisberg, B.; et al. Frequency of hippocampal formation atrophy in normal aging and Alzheimer's disease. Neurobiol. Aging, 18(1):1-11, 1997.

Deng, F.; Jiang, X.; Zhu, D.; Zhang, T.; Li, K.; Guo, L. \& Liu, T. A functional model of cortical gyri and sulci. Brain Struct. Funct., 219(4):1473-91, 2014.

Fischl, B. \& Dale, A. M. Measuring the thickness of the human cerebral cortex from magnetic resonance images. Proc. Natl. Acad. Sci. U. S. A., 97(20):11050-5, 2000.

Fischl, B.; Sereno, M. I.; Tootell, R. B. H. \& Dale, A. M. High-resolution intersubject averaging and a coordinate system for the cortical surface. Hum. Brain Mapp., 8(4):272-84, 1999.

Gregg, R. V. Tannic acid-iron alum reactions: stain of choice for macroscopic sections of brain to be embedded in plastic. Stain Technol., 50(2):87-91, 1975 .
Jack, C. R. Jr.; Petersen, R. C.; Xu, Y. C.; Waring, S. C.; O'Brien, P. C.; Tangalos, E. G.; Smith, G. E.; Ivnik, R. J. \& Kokmen, E. Medial temporal atrophy on MRI in normal aging and very mild Alzheimer's disease. Neurology, 49(3):786-94, 1997.

Janssen, J.; Reig, S.; Alemán, Y.; Schnack, H.; Udias, J. M.; Parellada, M.; Graell, M.; Moreno, D.; Zabala, A.; Balaban, E.; et al. Gyral and sulcal cortical thinning in adolescents with first episode early-onset psychosis. Biol. Psychiatry, 66(11):1047-54, 2009.

Joshi, S. C.; Miller, M. I. \& Grenander, U. On the geometry and shape of brain sub-manifolds. Int. J. Pattern Recognit. Artif. Intell., 11(8):1317-43, 1997.

Kandel, E. R.; Schwartz, J. H. \& Jessell, T. M. Principles of Neural Science. New York, McGraw-Hill, 2000.

Kaye, J. A.; Swihart, T.; Howieson, D.; Dame, A.; Moore, M. M.; Karnos, T.; Camicioli, R.; Ball, M.; Oken, B. \& Sexton, G. Volume loss of the hippocampus and temporal lobe in healthy elderly persons destined to develop dementia. Neurology, 48(5):1297-304, 1997.

Kiernan, J. A. \& Hudson, A. J. Frontal lobe atrophy in motor neuron diseases. Brain, 117(Pt. 4):747-57, 1994.

Meneses, M. S.; Montano Pedroso, J. C.; Fuzza, R. F. \& Milano, J. B. Comparative analysis of human brain slices with three different staining techniques. Arq. Neuropsiquiatr., 62(2A):276-81, 2004.

Miller, M. I.; Christensen, G. E.; Amit, Y. \& Grenander, U. Mathematical textbook of deformable neuroanatomies. Proc. Natl. Acad. Sci. U. S. A., 90(24):11944-8, 1993.

Rosas, H. D.; Liu, A. K. Hersch, S.;Glessner, M.;Ferrante, R. J.; Salat, D. H.; van der Kouwe, A.; Jenkins, B. G.; Dale, A. M. \& Fischl, B. Regional and progressive thinning of the cortical ribbon in Huntington's disease. Neurology, 58(5):695-701, 2002.

Paus, T.; Otaky, N.; Caramanos, Z.; MacDonald, D.; Zijdenbos, A.; D'Avirro, D.; Gutmans, D.; Holmes, C.; Tomaiuolo, F. \& Evans, A. C. In vivo morphometry of the intrasulcal gray matter in the human cingulate, paracingulate, and superior-rostral sulci: hemispheric asymmetries, gender differences and probability maps. J. Comp. Neurol., 376(4):664-73, 1996.

Talairach, J. Atlas D'Anatomie Stéréotaxique du Télencéphale. Études Anatomo-Radiologiques. Paris, Masson, 1967.

Thompson, P. M.; Hayashi, K. M.; de Zubicaray, G.; Janke, A. L.; Rose, S. E.; Semple, J.; Herman, D.; Hong, M. S.; Dittmer, S. S.; Doddrell, D. M.; et al. Dynamics of gray matter loss in Alzheimer's disease. J. Neurosci., 23(3):994-1005, 2003.

Van Essen, D. C.; Drury, H. A.; Joshi, S. \& Miller, M. I. Functional and structural mapping of human cerebral cortex: Solutions are in the surfaces. Proc. Natl. Acad. Sci. U. S. A., 95(3):788-95, 1998.

van Os, J. \& Kapur, S. Schizophrenia. Lancet, 374(9690):635-45, 2009.

Vonsattel, J. P. \& DiFiglia, M. Huntington disease. J. Neuropathol. Exp. Neurol., 57(5):369-84, 1998.

Walker, F. O. Huntington's disease. Lancet, 369(9557):218-28, 2007.

Watkins, K. E.; Paus, T.; Lerch, J. P.; Zijdenbos, A.; Collins, D. L.; Neelin, P.; Taylor, J.; Worsley, K. J. \& Evans, A. C. Structural asymmetries in the human brain: a voxel-based statistical analysis of 142 MRI scans. Cereb. Cortex, 11(9):868-77, 2001.

Zilles, K.; Armstrong, E.; Schleicher, A. \& Kretschmann, H. J. The human pattern of gyrification in the cerebral cortex. Anat. Embryol., 179(2):1739, 1988.

\section{Corresponding author:}

Azu Onyemaechi Okpara

Discipline of Clinical Anatomy

School of Laboratory Medicine and Medical Sciences.

Nelson R Mandela School of Medicine

University of KwaZulu-Natal

SOUTH AFRICA

Received: 17-04-2019

Accepted: 11-07-2019

Email: azu@ukzn.ac.za; oazu@unam.na 